\title{
Linguistic Analysis of Saudi Pidginized Arabic as Produced by Asian Foreign Expatriates
}

\author{
Hameed Yahya A. Al-Zubeiry \\ Department of English, Faculty of Science and Arts, Baljurashi, AlBaha University, AlBaha, KSA \\ E-mail: hameedyahya@gmail.com
}

Received: 17-08-2014

Accepted: 23-09-2014

Published: 01-03-2015

doi:10.7575/aiac.ijalel.v.4n.2p.47

URL: http://dx.doi.org/10.7575/aiac.ijalel.v.4n.2p.47

\begin{abstract}
This study aims at describing the system of SPA (Saudi pidginized Arabic) as produced by AFEs (Asian foreign expatriates) working in Saudi Arabia with specific reference to universal characteristics of reduction and simplification in the system of morpho-syntactic structure of Saudi Arabic. The study is based on data collected through a semistructured interview technique probing into the features of SPA system. Thirty informants were randomly selected from among expatriates working in Saudi Arabia and belonging to different linguistic backgrounds - Urdu, Hindi, Bengali, Tagalog, Indonesian, and Malayalam- as representatives of AFEs. The study showed that the AFEs tend to use simplified and reduced system of SA in order to communicate with its native speakers. This was reflected in producing variations of sentence word order that are not compatible with the sentence word order of SA, reduced inflectional verb forms and simplified noun phrase lacking agreement within its structure. The study concluded with the following implications: 1) SPA could be considered as an emerging contact variety among Asian expatriates in Saudi Arabic; 2) it has universal characteristics of reduction and simplification as shown in its structural system; 3) substrate languages play an essential role in the formation of the SPA.
\end{abstract}

Keywords: Pidgin, simplification, reduction, SPA, AFEs, SA.

\section{Introduction}

Communication in a multilingual and multicultural country brings about some effect on the native language of the host community. This effect can be realized in terms of linguistic changes at the different aspects of the native language systems namely, sound, structure and meaning. Such changes are observed in use among people when communicating in the language. Over a span of time, the newly formed contact language has become a lingua franka that is used for communication across the country.

\subsection{Rationale of the Study}

A Pidgin(ized) Arabic language has been in use as a medium of communication in the country of Saudi Arabia among a large number of foreign expatriates who have migrated into the country for labour purposes. According to Baker (1993: 6) pidgin "is a form of language created by members of two or more linguistic groups in contact as a means of intercommunication, the most basic grammatical rules of which are common to all its habitual users regardless of their own primary language, while at least one and perhaps all of the participating groups recognize that this means of intercommunication is not the primary language of any other." Trudgill (2000: 53), looks at the term pidgin as "a reduced, regularized, mixed language evolved for,..., trading purposes by speakers with no common language." Holm (2005: 5) defines pidgin as "a simplified language containing target language lexicon and including features of the speaker's first language." Sakoda and Siegel (2003: 1) refer to the term pidgin as "a new language that develops in a situation where speakers of different languages need to communicate but don't share a common language." The previous views of the situation and nature of pidgin call for describing the characteristics of the common language (i.e., Saudi pidginized Arabic) that is in use among the Asian foreign expatriates working in Saudi Arabia.

\subsection{Purpose of the Study}

The aim of the present study is to describe the system of Saudi pidginized Arabic (henceforth SPA) as produced by Asian foreign expatriates (henceforth AFEs) working in Saudi Arabia. It focuses on the universal characteristics of reduction and simplification in the system of morpho-syntactic structure of Saudi Arabic. The Saudi Arabic here refers to the colloquial form of Arabic spoken by the natives of the country. The scope of the study is limited to three major features of morpho-syntactic structure namely, sentence word order, verb phrase form, and noun phrase form.

\section{Literature Review \\ 2.1 Sociolinguistic Context}

Considering the definitions of the term pidgin mentioned earlier, the situation in Saudi Arabia is ideal for the crystallization of pidginized Arabic language. As Saudi Arabia is an oil-rich country, a large number of foreign expatriates flow into the country for having jobs. In view of the fact that Arabic is the native language of the country, the AFEs try hard to use it for communication with its native speakers. They, however, use a simplified version of the 
language which is known as 'Saudi pidginized Arabic' (SPA). The SPA is a reduced system of language that is used for communication between foreign expatriates and the native speakers of Saudi Arabic (henceforth SA). There are some factors that may lead to the existence of SPA in the context of Saudi Arabia. The following lines summarize these factors:

1) an immediate need on the part of the employees (foreign expatriates) to have contact with the employers (native speakers of SA) may force these foreign expatriates to use their language system with few words of SA;

2) social gap between the dominant community of native Arabs and the non-dominant community of foreign expatriates may not encourage them to learn the language of the host community;

3) heterogeneous linguistic backgrounds of the foreign expatriates' languages - like Hindi, Urdu, Bengali, Thai, Nepalese, Tamil, Tagalog, Sinhalese, and others - may force them to simplify and reduce the system of the target language (Arabic) so as to communicate with the Arabic-speaking community;

4) necessity of having a contact language (i.e., lexifier) among the expatriates leads to having a common language (SPA) to be used for communication among them;

5) the long period of living that the expatriates had in the host community may get them to be adapted to the new form of the SPA;

6) lack of Arabic language institutes in the country requires the new flowing expatriates to learn the SPA from their own country-men or co-workers.

Apart from the factors mentioned above, it is worthy to note that the strategies of language contact constantly followed by the foreign expatriates could create a sustainable language that has its new simplified and reduced system.

\subsection{Linguistic Features of Pidgin Languages}

Pidgin languages are usually based on the source (dominant) languages. They show some simplified and reduced linguistic features of the source languages. These features can be at the different linguistic levels of the contact language namely, phonology, morphology, syntax. At the phonological level, for instance, the pidgin speaker may recourse to his first language to simplify or reduce the intricate nature of the phonemic sounds of the contact language. Goodman's (1967), English Japanese Pidgin, Naess's (2008), Gulf Pidgin Arabic, Avram's (2010), the Romanian Pidgin of Arabic, and Salem's (2013), Asian Pidgin Arabic are typical example studies. Naess (2008: 33), for instance, maintains that Gulf pidgin Arabic speakers tend to replace the Arabic interdental fricative sound $/ \theta /$ to $/ \mathrm{t} /$ and $/ \mathrm{d} /$ to $/ \mathrm{d} /$ in pronouncing Arabic words like, 'tānī' - $\theta \bar{a} n \overline{1}-$ (another) and 'hāda' - hāoa - (this). Likewise, the Romanian Pidgin Arabic speakers replace some Arabic consonants such as the pharyngeal voiceless fricative $/ \mathrm{h} /$ and the velar voiceless fricative $/ \chi /$ with more typologically common phonemes like /h/ and / $/$ respectively (Avram, 2010 cited in Almoaily, 2012). They, for example, pronounce words like 'hut' (to put) as 'hut' and ' $\chi a l a s '$ (finished) as 'kalas'. At the morpho-syntactic level, simplification and reduction of grammatical feature is readily to be noticed in the speakers' pidgin language. In English, for example, an absence of any complex grammatical morphology is a common feature among the pidgin of English. The inflectional morphemes -'s (plural) and -'s (possessive) on nouns in standard English are scarcely used in pidgins (Yule, 2006: 202). Similarly, in Arabic, pidgin does not show inflections that indicate any grammatical aspect. For example, the verb in Arabic is used in its 'unmarked' form with no inflections to specify the usual verbal attributes, such as tense, aspect, and agreement in number, gender, and person (Bakir, 2010). Reduction of pronominal clitics is another morpho-syntactic feature of Arabic pidgin. It is noticed that Gulf Pidgin Arabic has no object clitics in the verb system as Gulf Arabic shows. In fact, all pronouns are independent and never morphologically bound to the verb (Bakir, 2010: 9). A pidgin speaker of Arabic may produce a sentence like, 'mudeer ab9a inta' - mudeer yeb9ak- (the manager wants you). Sebba (1977) describes the reduction structure system by means of the following four design features ascribed to pidgin grammars: (1) The syntactic features of a pidgin reveal a lack of surface grammatical complexity; (2) Pidgins are characterized by a lack of morphological complexity; (3) they show a general preference for semantic transparency and; (4) they show a characteristic reduction in vocabulary.

\subsection{Previous Related Studies}

A number of related studies have investigated the pidginized forms of Arabic language in Gulf countries. Smart's (1990), pidginization in Gulf Arabic, was the earliest study. The researcher aimed to describe the variety of pidginized forms of Arabic in gulf countries. The study was based on printed material (cartoon captions imitating the language of workers) published in two gulf-country newspapers between the years 1986 and 1987 . This was also supplemented by the researcher's personal observations (1966-1987) of the immigrant communities which consist of skilled and unskilled manual workers, taxi drivers and shopkeepers. The study focused on the phonological, morphological and syntactic components of the pidginized Gulf Arabic. Smart divided the pidginized verb forms into three: Y (V) prefixed type, the unstable type, and the imprefixed type. He also observed that the GA SG Masc. demonstrative ' $h a d h a$ ' is the usual form used to refer to all genders and numbers. He maintained that the overuse of the demonstratives is connected with the use of demonstrative pronouns in Urdu to convey the force of a definite article.

Another study was done by Naess (2008) describing Omani Pidgin Arabic. Its aim was to describe the GPA structures and compare it to Gulf Arabic. Three grammatical features were studied namely, possessive marking, negation and the verbal system. The study was based on recorded interviews conducted with male and female immigrant workers who are mainly from Southeast Asia. Naess concluded that reduction and simplification are two common features observed in the GPA grammar. Reduction was seen in the emergence of a light verb system, where 'sawwi' - to do' is used to create compound verbs from nouns and adjectives. Another striking reduced feature of GPA, according to Naess, was in the verbal system. She observed that words, which in Gulf Arabic are verbal nouns, are treated as verbs rather than 
nouns in the corpus of the study. Simplification, on the other hand, was noticed in deriving nouns and verbs with related meanings by applying different morphological patterns to the same consonant root. Mother tongue of the substrate languages speakers was another factor influencing the GPA speakers. This was reflected in the frequent reduction of the number of morphemes in one word and the preference of analytic structures.

Bakir (2010) undertook a study aiming at describing the GPA reduced verbal system which is in use in various countries of the Western coast of Arab gulf and Saudi Arabia. The study was based on data collected from recordings of conversations with 10 Asian expatriate speakers whose mother tongue is non-Arabic. Bakir found out that the GPA system exhibits the general properties of grammatical simplification and reduction that such systems are characterized with. The verb in GPA is 'unmarked' for tense, person, aspect, gender, and number, and that only one form is used to indicate difference in tense, aspect, mood, and voice. He claimed that the common verb used in GPA is the $3^{\text {rd }}$ singular masculine imperfect form: 'yiji-come', 'yabi-want' (with a variant yibgha), and 'yaakid-take', being used for 1SG, 2 SG Masc., and Fem., and 3 PL. subjects in addition to different references to past and future. Bakir added that tense can only be inferred from context or by the existence of some adverbs of time. He also noticed that the aspect markers are absent and the progressive aspect of the verb can be indicated by the use of the speakers' GPA particle 'fii'.

In Saudi Arabia, Al-Zarqawi (2010) made an attempt to describe the variety of Saudi Pidgin Arabic spoken by Indians, Bangladeshis, Indonesians and Filipinos in Al-Ahsa province, in the eastern region of the country. The study was based on six hours of data from TV series, 15 hours of tape-recorded spoken data and test sentences designed to elicit certain forms by focusing on word order and structural features. Al-Zarqawi argued that the term 'Gulf Pidgin' would be too broad and may subsume other potential pidgin varieties. Accordingly, she suggested distinguishing the pidgin she analyzed as 'an Asian variety'. She added that the Asian pidgin variety is characterized by the mother tongues which form the substrate language.

Al-Moaily (2012) conducted a study that aimed at investigating language variation in GPA resulting from the morphosyntactic differences in the speakers' L1s and from their length of stay in the Gulf. The data-base for the study consisted of interviews with sixteen informants from three linguistic backgrounds: Malayalam, Bengali, and Punjabi. The interviews were conducted in two cities in Saudi Arabia: Riyadh and Alkharj. The analysis was based on ten morphosyntactic phenomena: free or bound object or possessive pronoun, presence or absence of the Arabic definiteness marker, presence or absence of Arabic conjunction markers, presence or absence of the GPA copula, and presence or absence of agreement in the verb phrase and the noun phrase. The finding of the study showed that both first language and number of years of stay in the Gulf seem to have little effect on the informants' choices of morpho-syntactic features. Conjunction was the only variable of the six above which exhibited a significant relation between the informants' L1 and their choice among GPA variables. The two features: Object and possessive pronouns and verbal agreement were developmental pidgin shifted towards a variety different from the superstrate language, GA.

A recent study has been done by Albakrawi (2013) in Tabuk. The main purpose of the study was to investigate the linguistic effect of the Asian workers on Saudi Arabic variety. Tape-recorded and planned interviews were used to collect the data. The findings of the study indicated that the local Saudi Arabic variety is influenced linguistically by the Asian workers in the following linguistic areas: lack of inflections, determiner, quantifier, word order, negation, copula and verb form and they are compatible with pidgin universals.

The following study attempts to describe the system of the SPA as produced by the AFEs working in Al-baha, southern region of Saudi Arabia. It focuses on the universal characteristics of reduction and simplification in the system of morpho-syntactic structure of Saudi Arabic (i.e., sentence word order, verb phrase form, and noun phrase form).

\section{Methodology}

The current study is qualitative in nature. It aims to probe into the system of the SPA used by the AFEs who are working in Saudi Arabia. A semi-structured interview technique was used to elicit data about the features of SPA system. Thirty informants were randomly selected from among expatriates working in Saudi Arabia and belonging to different linguistic backgrounds - Urdu, Hindi, Bengali, Tagalog, Indonesian, and Malayalam - as representatives of AFEs. Five informants from each language were interviewed individually for 25-30 minutes at their working places. Firstly, they were requested to give a brief profile about themselves that includes: name, nationality, period of stay in the country, occupation. Secondly, they were involved in having conversations about general topics namely, their family life, their daily routines, nature of their work, and life difference in their own countries. It is believed that having such general topics is an effective technique assuring to have systematic and comprehensive data. After the interviews were administered, the recorded data was transcribed in order to be analyzed and described. It is worthy to mention that most of the informants who were interviewed have been working in the country for a period ranged between 4-10 years.

\section{Analysis and Discussion}

The present study aims at describing the SPA system as produced by AFEs with reference to three morpho-syntactic features namely, sentence word order, verb phrase form, and noun phrase form. These SPA features are analyzed and described as follows:

\subsection{Sentence Word Order}

The word order in sentence is a universal feature of a pidignized language of contact. The data analyzed has shown that the AFEs constantly produce sentence word order variations in their communication of SA. These variations are 
observed in terms of misplacing some elements of sentence in an order that does not conform with the order of that in SA. For convenience of presentation, we summarize the types of sentence elements misplaced in the following table:

Table1. The SPA of the AFEs in Sentence Word Order

\begin{tabular}{|c|c|c|}
\hline $\begin{array}{c}\text { Misplaced } \\
\text { Sentence } \\
\text { element }\end{array}$ & SPA word order & SA word order \\
\hline 1.Subject & $\begin{array}{l}\text { Akel sawi hurma fi bait. (OVS) } \\
\text { food-make-1SG sub. -at home. }\end{array}$ & $\begin{array}{l}\text { tesawi al-hurmah al-akel fi al-bait. (VSO) } \\
\text { Make - art.-woman- art. food- at home. } \\
\text { (the woman makes food at home.) }\end{array}$ \\
\hline 2.Verb & $\begin{array}{l}\text { Ana kubez akul. (SOV) } \\
1 \mathrm{SG} \text { sub.- bread - eat }\end{array}$ & $\begin{array}{l}\text { Akul khubez. (VSO) } \\
\text { Eat- (implicit } 1 \mathrm{SG} \text { sub.) - bread } \\
\text { (I eat bread.) }\end{array}$ \\
\hline 3.Object & $\begin{array}{l}\text { Zabun ana kalem. (OSV) } \\
\text { Customer - } 1 \text { SG sub.- speak to }\end{array}$ & $\begin{array}{l}\text { Akalem al-zabun. (VSO) } \\
\text { Speak to-(implicit } 1 \mathrm{SG} \text { sub.) - art. customer } \\
\text { (I speak to the customer.) }\end{array}$ \\
\hline 4.Predicate & $\begin{array}{l}\text { Kabeer hadha bab. (Pred. S) } \\
\text { Big - det. door. }\end{array}$ & $\begin{array}{l}\text { Hadha al- bab kabeer. (S Pred.) } \\
\text { Det. - art. door - big. } \\
\text { (This door is big.) }\end{array}$ \\
\hline
\end{tabular}

Looking at the different variations of sentence word order produced by the AFEs, we realize that they are not compatible with the sentence word order of SA. Examples 1-3 show that the order of the sentence elements (i.e., subject, verb, and object) is misplaced. Example 4 indicates that the order of the predicate 'kabeer-big' element is inverted with its subject 'hadha bab-this door'.

In fact, Arabic has two main types of sentence namely, verbal sentence and nominal/equational sentence. The verbal sentence is the one which begins with a verb, whereas the nominal sentence is that which begins with a noun. Another distinction between them is made on the basis of whether the sentence contains a verb or not. The sentence which has verbless predicate is called "equational sentence" and the one whose predicate has a verb is called "verbal sentence" (Ryding, 2008). The word order of the verbal sentence is VSO (Verb - Subject - Object) whereas that of the nominal sentence is S - P (Subject - Predicate).

The nature of the Asian languages may account for the production of such variations in sentence word order. The common word order in sentence structure of Asian languages like, Urdu, Hindi, Bengali, and Malayalam, follows the pattern of SOV (Meyer, 2009:36). Such a word order type is likely to be transferred from the substrate languages in order to simplify the structure of superstrate language and consequently pidgin structure is formed and commonly used among the AFEs. As for the word order of the sentences OVS and OSV, it is believed that they are produced as a result of derivation process. According to generative grammar, SOV is the basic sentence word order and OVS and OSV are derived through sentence elements movement. The inverted structure of (S Pred.) could be attributed to the preference of using the predicate 'marked' sentence among the AFEs. In fact, it has been observed that the AFEs prefer to use the predicate at the beginning of the sentence.

\subsection{Verb Phrase Form}

The form of Arabic verb phrase is considered to be complex. It carries a dense morphological composite that denotes different grammatical aspects of the language like, tense, aspect, voice and agreement in number, gender and person. The complexity of such interrelated grammatical denotations is likely to force the Asian speakers of Arabic to reduce the Arabic verb forms and use simplified ones for their contact language. The analysis of the AFEs' pidginized verb phrase forms shows that the AFEs tend to use reduced and simplified verb forms that lack morphological affixes indicating the grammatical aspects of the language. The table below summarizes these verb forms:

Table 2. The SPA of the AFEs in Verb Phrase Form

\begin{tabular}{|c|c|c|}
\hline Verb form & SPA verb form & SA verb form \\
\hline \multirow[t]{2}{*}{ 1. Tense Marker } & Ana awal yaji umrah & Ana jet le umrah men gabel. \\
\hline & 1SG sub. - before- come - umrah & $\begin{array}{l}\text { 1SG sub. - came - for umrah - before. } \\
\text { (I had Umrah before.) }\end{array}$ \\
\hline \multirow[t]{3}{*}{ 2. Aspect Marker } & a. Ana $f i$ sawi masora & a. Ana qa'ad asaleh almasora. \\
\hline & $1 \mathrm{SG}$ sub. -prog. marker-fix- pipe. & $\begin{array}{l}1 \text { SGD- prog marker-fix the pipe. } \\
\text { (I am fixing the pipe.) } \\
\text { b. qad rah-Al-mudeer. }\end{array}$ \\
\hline & $\begin{array}{l}\text { b. mudeer kalas ruh. } \\
\text { Manager-perfect marker (go- you } 2 \\
\text { SG). }\end{array}$ & $\begin{array}{l}\text { Has gone - art.- manager. } \\
\text { (The manager has gone.) }\end{array}$ \\
\hline
\end{tabular}




$\begin{array}{ll}\text { 3. Person Marker } & \text { Ana yajeeb hajer. } \\ & \text { 1SG sub. - bring - block. }\end{array}$

4. Gender Marker

hurmah - yajles - bait. Woman-Masc. marker- stay-house.

5. Number Marker Katheer nafer sheel hadha A lot of people - take - this

6. Verbal Noun
Ana shughel kayat. 1SG sub. - work- tailor.
Ajeeb hajer.

Bring- 1SG sub. (implicit) - block

(I bring a block.)

Hurma tajles fi albait.

Woman-Fem. marker-stay- in art.

house.

(The woman stays at home.)

Katheer naas yasheelun hadha.

A lot of people - take - plural marker this

(A lot of people take this.)

Ashtaghel khayat.

Work - 1SG sub. (implicit)- tailor.

(I work as a tailor.)

Considering the variations of the verb phrase form produced by the AFEs in table 2 above, we notice that the imperfect 3 SG Masc. verb form 'yaji - come', in example 1, is used in place of the SA perfect verb form 'jeet-came'. Interestingly, it has been observed that the AFEs usually use the time adverb 'awal' to indicate the perfect tense and keep using the common simplified verb form prefixed with the imperfect 3 SG Masc. marker ' $y$-'.

As for the aspect marker of the verb form, it has been observed that the AFEs tend to use a certain particle and expression denoting the verb aspect of the language. Example 2 (a) shows that the particle ' $f$ ' ' is used to indicate the progressive aspect of the pidginzed verb form. SA, however, uses the particle 'qa' aed' denoting the progressive aspect of the verb action. Likewise, in example 2 (b) the expression 'kalas' is used to denote the perfect aspect of the verb action. It is worthy to note that the verb form 'ruh' expresses the meaning of 'you go' rather than 'he has gone'.

With regard to the person marker of the verb form, it has been observed that the 3 SG Masc. marker ' $y$-' is commonly prefixed to the verb form. Person marker can be retrieved from either the context or through the use of separated personal pronouns. Arabic person marker follows the clitics system affixed to the verb. It is important to mention that plurality markers are not used in the pidginized verb forms produced by the AFEs. The 2 SG Masc. pronoun 'enta(you)' and the SG Masc. proximal demonstrative pronoun 'hadha-this' are commonly used.

As far as the gender marker is concerned, the analysis indicates that the pidginized verb form does not agree with the sentence subject in gender. Example 3 shows that the feminine subject 'hurmah - woman' does not agree with the reduced verb form ' $y$ aruh-go' which is prefixed with the 3 SG Masc. marker ' $y-$ '. Speakers of SA always prefix the verb form with the $3 \mathrm{SG}$ Fem. marker ' $t$-' (taruh-go) in order to have subject verb agreement in gender. Likewise, Example 4 shows that the pidginized verb form 'sheel-take' does not agree with the sentence plural subject 'katheer nafer - a lot of people'. In fact, the reduced verb form 'sheel - take' has the imperative mood of the root past verb form 'shala - took' and it is frequently used to refer to a declarative mood. It is worthy to note also that the typical pidginized word 'nafer-person/people', which is commonly used to refer to a singular as well as plural noun, gets the AFEs resort to use the reduced form of the verb. The SA verb form, 'yasheelun -take', agrees with the sentence plural subject 'katheer naas - a lot of people' in number.

One of the most striking pidginized verb forms observed in the data is the recurrence of the use of verbal nouns like, 'kalam-speech', 'shughel-work' and 'akel- eat' in a grammatical context of verb form structure. Example 6 shows that the simplified verbal noun 'shughel- work' is used instead of the SA verb form 'ashtaghel- to work'.

\subsection{Noun Phrase Form}

There are some inflectional features that characterize Arabic noun phrase. These features are realized in terms of gender, number, humanness, definiteness, and case (subject of the verb or object of a preposition). The grammatical context of the noun manifests these features and shows compatibility and agreement within the phrase or the verb and its subject. To have control over the appropriate use of such inflectional features might be difficult for non-native speakers of Arabic. In fact, it is noticed that the AFEs ignore using these features when communicating with the native speakers of SA. They tend to use reduced and simplified forms of noun phrase that lack compatibility and agreement across the language structure. The following are some observed variations of the pidginized noun phrase form:

Table 3. The SPA of the AFEs in Noun Phrase Form

\begin{tabular}{|c|c|c|}
\hline Noun Form & SPA Noun form & SA Noun Form \\
\hline $\begin{array}{l}\text { 1. Definite Marker } \\
\text { (article) }\end{array}$ & $\begin{array}{l}\text { Wadi buzorah madrasah. } \\
\text { Take - children - school. }\end{array}$ & $\begin{array}{l}\text { Awadi al-buzorah al-madrasah. } \\
\text { Take - art. children - art.- school. } \\
\text { (Take the children to school) }\end{array}$ \\
\hline $\begin{array}{l}\text { 2. Agreement } \\
\text { between: } \\
\text { a-Noun \& Adjective }\end{array}$ & $\begin{array}{l}\text { a. fih bint kabeer } \\
\text { There is - girl - old- Masc. marker } \\
\text { (implicit). }\end{array}$ & $\begin{array}{l}\text { a. Andi bint kabeerah. } \\
\text { Have - } 1 \mathrm{SG} \text { - girl - old- Fem. } \\
\text { marker } \\
\text { (I have an old girl.) }\end{array}$ \\
\hline
\end{tabular}


b-Noun \&

Determiner

3. Plural Marker

Khamsah sana shughel hena.

Five year - work - here.

4. Possessiveness b. Hadha sharekah khams sanah.

This - company - five year.
b.Fi hadhih alsharekah khams

sanahwat

in this company five years.

(Five years in this company.)

Khams sanawat Ashtaghel hena.

Five years - work $-1 \mathrm{SG}-$ here.

(I have been working here for five

years.)

Esmi taha

\author{
Name - 1 SG poss. - taha \\ (My name is Taha.) \\ Shuft sayara-tak \\ Saw -1SG (implicit) -car - your \\ (I have seen your car.) \\ b. Ana ashuf sayarah enta \\ $1 \mathrm{SG}-\mathrm{saw}-\mathrm{car}-2 \mathrm{SG}$ sub. \\ 1 SG sub. - name - 3SG marker- \\ Taha
}

Looking at the variations of the above pidginized noun phrase forms, we notice that in example 1, the definite prefix marker 'al-' is deleted from both the noun object phrase 'buzorah-children' and the noun object of a preposition 'madrasah-school' in a grammatical context requiring the definite marker. The deletion of the definite article in the pidginized noun phrase could be traced back to the fact that most of the substrate languages lack the definite article in their grammar (Sharma, 2005).

Variation in agreement within the structure of the noun phrase form and its modifiers is another pidginized form of noun phrase. Example 2 (a) indicates that the noun phrase 'bent kabeer-old girl' lacks agreement within the phrase itself. In fact, the feminine noun 'bent-girl' should agree with the postmodifier '*kabeer-old' in gender. The SA noun phrase 'bent kabeera' shows agreement between the feminine noun 'bent-girl' and its postmodifier 'kaberah-old' by adding the inflectional feminine marker '-ah'. Likewise, the noun phrase 'hadha sharekah - this company' in example 2 (b) lacks agreement within the phrase structure. However, the lack of agreement here can be realized between the feminine noun 'sharekah - company', and its masculine determiner 'hadha -this'. Unlike English, SA shows agreement within the structure of the noun phrase in terms of gender and number between the noun and its modifiers/determiners. In fact, it has been observed that the AFEs tend to simplify the structure of the noun phrase by using common forms of postmodifier and the determiner ' $h a d h a$ ' that both agree only with ' $3 S G$ Masc. noun' in most of the cases of the noun form.

Example 3 shows that the noun 'sanah-year' lacks its plural marker which is determined from the grammatical context as it is preceded by the numeral quantifier 'khamsa-five'. SA manifests agreement between the noun and the preceding quantifier in number. This can be shown by adding the inflectional suffixes '- $a t$ ' referring to the prospective grammatical aspect. So, the quantifier 'khamsa-five' is followed by a plural noun 'sanawat-years.

Possessiveness is another pidginized variation of noun phrase form. It has been observed that the AFEs tend to use common pidginized forms when expressing possessiveness. Example 4 (a) shows that the $1 \mathrm{SG}$ subject pronoun 'ana- $I$ ' precedes the possessed noun 'esmu- name'. However, example 4 (b) indicates that the 2 SG 'enta-you' follows the possessed noun 'sayarah-car'. In fact, the $1 \mathrm{SG}$ subject pronoun 'ana- $I$ ' and the $2 \mathrm{SG}$ enta-you' subject pronouns are frequently used instead of the correct inflectional suffixes which should agree with possessor in number and gender. SA possessiveness is expressed by adding inflectional suffixes that agree with possessor in number.

\section{Conclusion}

The study aimed at describing the SPA system as produced by AFEs with reference to three morpho-syntactic features namely, sentence word order, verb phrase form, and noun phrase form. The findings of the analysis concluded that the AFEs tend to simplify and reduce the system of SA in order to communicate with its native speakers. With reference to sentence word order, it has been observed that the AFEs produced variations of sentence word order that are not compatible with that of SA. The sentence pattern (SOV) of the Asian languages under study could account for the production of pidginized misplaced sentence elements by the AFEs in their contact language. The inverted word order of subject predicate is likely to be attributed to the preference of using the predicate 'marked' sentence among the AFEs.

As for the verb phrase forms, it has been reported that most of the pidgnized verb forms show reduced verb inflection and tense is denoted by the use of certain separated particles expressing time. A common simplified verb form was realized in the use of the prefixed verb, the 3 SG Masc. marker ' $y$-', in expressing gender and person. Another simplification of the verb form produced by the AFEs was observed in treating verbal nouns as verbs.

With regard to noun phrase form, the study concluded that the AFEs tend to produce reduced and simplified forms of noun phrase that lack compatibility and agreement within its structure. This has been observed in terms of deletion of a context-required definite article ' $a$ l-the' and plural marker inflectional suffixes and a frequent use of common forms of postmodifier and determiner ' $h a d h a$ ' that both agree only with '3 SG Masc noun' in most of the cases of the noun form. Possessiveness in noun phrase was frequently expressed by the use of the $1 \mathrm{SG}$ subject pronoun 'ana- $I$ ' and the $2 \mathrm{SG}$ enta-you' subject pronouns instead of the correct inflectional suffixes which should agree with possessor in number. 
In view of the findings of the study, the following implications can be drawn: 1) SPA could be considered as an emerging contact variety among Asian expats in Saudi Arabic; 2) it has universal characteristics of reduction and simplification as shown in its structural system; 3) substrate languages play an essential role in the formation of the SPA.

\section{References}

Al-Azraqi, M. (2010). Pidginization in the Eastern region of Saudi Arabia: Media Presentation, in Arabic and the media, linguistic analysis and application (Book), Ed. Reem Bassiouney, Brill, Leiden. Boston, 159-173.

Albakrawi, H. (2013). The Linguistic Effect of Foreign Asian Workers on the Arabic Pidgin in Saudi Arabia. Journal of Research on Humanities and Social Sciences, 9 (2), 127-133.

Al-Moaily, M. (2012). Language Variation in Gulf Pidgin Arabic. Unpublished Ph. D thesis, Newcastle University: UK.

Avram, A. (2010). An outline of Romanian Pidgin Arabic'. Journal of Language Contact, 3, 20-38.

Bakir, M. (2010). Notes on the verbal system of Gulf Pidgin Arabic. Journal of Pidgin and Creole Languages, 25 (2), 201-228. http://dx.doi.org/10.1163/000000010792317884.

Goodman, J. (1967). The Development of a Dialect of English-Japanese Pidgin. Anthropological Linguistics, 9 (1), 43 55.

Holm, J. (2000). An introduction to pidgins and creoles. Cambridge: Cambridge University Press.

Meyer, C. (2009). Introducing English linguistics. Cambridge: Cambridge University Press.

Naess, U. (2008). Gulf Pidgin Arabic: Individual strategies or structured variety. MA thesis, University of Oslo, Norway.

Ryding, K. (2008). A reference grammar of Modern Standard Arabic. Cambridge: Cambridge University Press.

Sakoda, K. \& Siegel, J. (2003). Pidgin Grammar: an introduction to the Creole English of Hawai'i. Honolulu, Hawaii: Bess Press.

Salem, A. (2013). Linguistic Features of Pidgin Arabic in Kuwait. English Language Teaching, Canadian Center of Science and Education, 6 (5), 105-110. http://dx.doi.org/10.5539/elt.v6n5p105.

Sebba, M. (1997). Contact Languages, Pidgins and Creoles. London: Macmillan.

Sharma, D. (2005). Language transfer and discourse universals in Indian English article use. SSLA, 27, 535-566. http://dx.doi.org/10.1111/j.1360-6441.2005.00290.x.

Smart, J. (1990). Pidginization in Gulf Arabic: A First Report. Anthropological linguistics, 32(1-2), 83-119.

Trudgill, P. (2000). Sociolinguistics: An introduction to Language and Society (4 $4^{\text {th }}$ edn). London: Penguin. Yule, G. (2006). The Study of Language ( $3^{\text {rd }} e d n$ ). New York: Cambridge University Press. 